\title{
Adaptación cristiana de las defensas de la Alcazaba de Almería durante el siglo XVI
}

Christian adaptation of the defences of the Alcazaba of Almeria during the sixteenth century

\section{Diego Garzón Osuna}

Universidad de Granada, Granada, Spain, dgo.arquitecto@gmail.com

\begin{abstract}
After the capitulation of the nasrid city of Almería (1489), the new Castilian administration was able to verify the state of ruin of its defences due to the earthquake of 1487, ordering the rapid construction of a castle on the highest point of the battered hispano-muslim Alcazaba.

Between 1490 and 1502 the castle was built, incorporating in its design the most effective systems of the time to repel an attack with gunpowder. The typological references of this military installation correspond to the School of Valladolid; with a long tradition in the construction of castles.

In parallel with the completion of these works, the Catholic Monarchs ordered in 1501 to armor the defence of the coasts of the Kingdom of Granada, articulating and extending the medieval system of watchtowers scattered along the coast, to counteract the fragility of the annexed territories, the mestizaje of its people, and the proximity of Africa. Thus concluded the works in the Castle, the works were centred in the repair of the walls of the city, action that will extend to the fences of the Alcazaba (1526).

Towards 1547, attacks by turkish and berber pirates followed one another on the Almeria coast in the face of the defencelessness of the population. These incursions led to concern about the proper conservation of military installations. As a consequence of this, the old Alcazaba was adapted to the distant war offered by the use of gunpowder.

The first interventions were designed by Luis de Machuca, architect of the Palace of Carlos V in the Alhambra. This accommodation included the construction of the bastions of the Campana (1550) and the repair of the doors of Justice and the Guard (1565), completing the program due to the proximity of the War with the Moriscos, with the construction of the bastions of the San Matías and Espolón (1568).
\end{abstract}

Keywords: Christian, fortress, medieval, Almeria.

\section{Introducción. Los orígenes de la fortaleza}

Los orígenes de la Alcazaba de Almería se remontan a mediados del siglo $\mathrm{X}$, momento en el que el califa Abd al-Rahman III atendiendo al valor geoestratégico del puerto de Almería mandó transformar el enclave en una ciudad fortificada (Torres, 1957, pp. 411-453).

Junto a la construcción de un cinturón defensivo de murallas se establecieron equipamientos civiles, religiosos y militares afines al nuevo rango administrativo de la metrópoli, sobresaliendo entre ellos la elevación de una fortaleza. El emplazamiento elegido para la Alcazaba fue un risco aislado a retaguardia. Excepcional otero utilizado en época romana y emiral por sus condiciones para la vigilancia del tráfico marítimo. 
Durante la edad media la Alcazaba se adaptó progresivamente materializando múltiples ampliaciones, reparaciones y reformas en sus recintos y fortificaciones con los que dar respuesta al paso del tiempo, a los hechos de guerra y a los distintos moradores que la ocuparon: taifas, almorávides, cristianos (1146-1156), almohades y nazaríes.

En todos los casos la fortaleza albergó la residencia del poder civil, así como una guarnición militar estable con la que defender la ciudad en caso de asedio. Su distribución se configuró en tres grandes recintos o retiradas divididos por murallas, respondiendo al aprovechamiento y funcionalidad militar del risco. De este modo en el punto más bajo se situó el ingreso a la fortaleza y junto a él, una gran área castrense destinada a albacar y a campamento de la tropa (primer recinto). El segundo acogió a la administración general de la ciudad, reservando el punto más elevado e inexpugnable a un Alcázar (tercer recinto); pieza que será reemplazada con urgencia por los Reyes Católicos, respondiendo a la invalidez que presentaba la fortaleza a causa de un terremoto acaecido en 1487.

\section{La administración castellana y la defensa del territorio}

La llegada de la edad moderna a la Alcazaba de Almería se enmarca en un largo periodo bélico conocido como la Guerra de Granada (14821492) fruto del cual los Reyes Católicos obtendrán los últimos territorios hispanomusulmanes de la península Ibérica gobernados hasta entonces por la dinastía nazarí.

Con la rendición de Málaga en 1487 en favor de Castilla, el combate se trasladó hacia la frontera oriental de Almería con la intención de cercar Granada y acelerar el fin de la contienda. Dominios que junto a las ciudades de Guadix y Baza pertenecían a Abū Abd Allāh Muhammad azZaghall, en virtud del reparto del reino de Granada acordado con su sobrino Boabdil en 1486.

Pero la táctica cristiana encontró en noviembre de 1487 un aliado inesperado al sufrir la ciudad de Almería un devastador terremoto causando graves destrozos en el caserío y en la fortificación de la ciudad, que había sido reforzada y reparada por El Zagal en fechas anteriores como medida para hacer frente a un eventual ataque cristiano. Cita el cronista Fernández Palencia (Fernández, 2012, p. 212):

"[la catástrofe] influyó principalmente en el terror, que se apoderó de todos los moros del territorio granadino. El terremoto que en noviembre derribó la torre más fuerte y la mayor parte de las murallas de Almería, y en nuevas y más terribles sacudidas destruyó cuanto Mahomat Abohardilles [el rey Abū Abd Allāh] había hecho reparar".

La desolación en que quedó la Alcazaba y la costosa reconstrucción que precisaba pudo ser la causa de la inacción de El Zagal. Esta decisión fue posible gracias a que los combates militares contra los cristianos se desplegaban en otras localizaciones alejadas de la capital.

Tras una larga campaña de asedio sobre la ciudad de Baza, el Zagal aceptó la capitulación honrosa que le ofrecía Fernando II de Aragón. En consecuencia, en diciembre de 1489 se firmaron los acuerdos de anexión a la corona de Castilla de las villas de Purchena, Tabernas, las Alpujarras y Almuñécar, incluyéndose además las ciudades de Baza, Guadix y la capital Almería.

El día 22 de diciembre se escenificó la entrega de llaves de las puertas de la ciudad de alMariyya (Almería), con la entrada de un sequito civil y militar encabezado por el Comendador Mayor de León, Don Gutierre de Cárdenas, Este consejero del rey Fernando fue a la vez nombrado nuevo alcaide de la fortaleza disfrutando desde entonces de su tenencia en pago a los servicios prestados a la corona durante la guerra. Es por ello que él será el designado para enarbolar en la Alcazaba, en la torre más alta que permanecía en pie tras el citado terremoto, la cruz y el pendón de Santiago junto al estandarte de los Reyes Católicos. Los mismos que tras comprobar el estado de ruina que presentaba la fortaleza, urgirán a su secretario Hernando de Zafra la rehabilitación del enclave con la construcción de un nuevo castillo artillero en sillería.

Con este equipamiento defensivo se cubrían las necesidades mínimas para asegurar la bahía frente incursiones marítimas de enemigos y 
piratas, extendiéndose los reparos al resto de cercas y torres que circunvalaban la ciudad, truncadas igualmente por la acción del seísmo. De este modo se aplicaba en Almería el blindaje de fronteras iniciado tiempo atrás en los principales núcleos y puertos a medida que la conquista los anexionaba; tal fue el caso de Gibraltar, Marbella, Fuengirola, Málaga, Vélez, Almuñécar o Salobreña.

La fortificación del litoral se materializó paulatinamente con la construcción o reutilización de torres, castillos y estancias, otrora hispanomusulmanas, diseminadas cada dos o tres leguas (de 8,40 a $12,60 \mathrm{~km}$ ) hasta generar una estrecha red de vigilancia costera.

Aunque las obras en los distintos núcleos fueron ejecutadas con premura, la ordenación militar integral de los enclaves y sus destacamentos se articuló años después gracias a la Instrucción para la defensa de la costa occidental del Reino de Granada de 13 de septiembre de 1497, siendo completada en 1501 con la Real Provisión que incluía la guarda y defensa del litoral oriental (Gámir, 1958, pp. 293-314).

\section{La traza del nuevo Castillo Cristiano}

Cuando llegaron las tropas castellanas a Almería, la Alcazaba mantenía sustancialmente la distribución original de recintos o retiradas implantada desde época califal (siglo X), conservando su materialización en tapial. Sistema constructivo ágil y económico formalizado con muros de tierra compactada en tongadas con cal aérea como aglomerante. Pero si algo puso de relieve la Guerra de Granada fue precisamente la vulnerabilidad de estas construcciones medievales ante el poder destructor de la pólvora en la guerra moderna. En consecuencia, ante el reto de adaptar este viejo bastión a las necesidades del momento, la administración castellana optó por la sustitución integral del sector occidental (donde se situaba el Alcázar), ocupando de este modo el punto más inexpugnable de la Alcazaba. Obra que despreciará una actuación extensiva quizás por su elevado coste.

Este nuevo castillo, del que no se conoce el arquitecto o ingeniero que le dio traza, destila un profundo conocimiento en poliorcética, reco- giendo de este modo la tradición castellana, con signos tipológicos, estilísticos y constructivos propios de una etapa de transición entre la evolución de los modelos de castillos diseñados por los maestros de la Escuela de Valladolid y la moderna arquitectura militar renacentista que se desarrollaba en Italia; capaz de soportar los efectos destructivos de las minas de pólvora.

El Castillo Cristiano de la Alcazaba de Almería se levantó entre 1490 y 1502 con una técnica constructiva mixta basada en grandes muros de hormigón de cal grasa forrados con sillería de piedra autóctona.

La implantación de este castillo aprovecha la gran altura del macizo rocoso en el que se asienta, ordenando un recinto militar formado por tres espacios principales: un Patio de Armas protegido por una muralla almenada salpicada de troneras y saeteras, en cuyos vértices se erigieron cubos o torres de flanqueo, una esbelta Torre del Homenaje precedida de puente levadizo, y una barrera artillera en la linde con el segundo recinto de la Alcazaba Vieja; acceso natural y única fachada que podía ser atacada a nivel (Fig. 1).

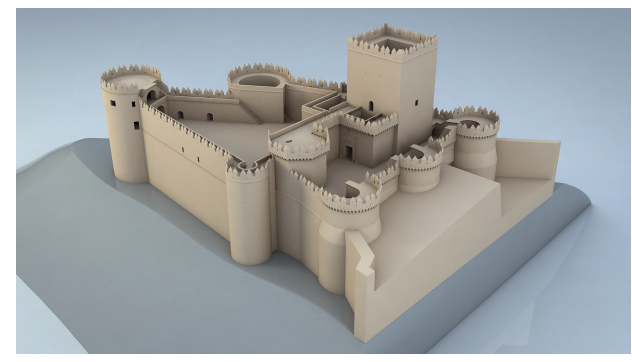

Fig. 1. Recreación virtual del castillo. Incluye el último cuerpo de la Torre del Homenaje que no llegó a ejecutarse (Autor).

Para comprender la distribución y los recursos estilísticos, constructivos y defensivos presentes en Almería a continuación se exponen aquellos castillos pretéritos cuyos rasgos guardan similitud o suponen referentes tipológicos en la evolución constructiva de la poliorcética castellana durante el siglo XV. Así la proporción y dimensiones de la Torre del Homenaje presente en Almería se asemeja a las del castillo de Fuensaldaña (Valladolid), construido en 1452. 
La implantación en el roquero tiene por su parte un precendente en el Castillo de Peñafiel (Valladolid). Fuerte reformado en la segunda mitad del siglo XV que adaptará sus murallas al perfil del cerro, defendiendo sus extremos con torres salientes -o espolones- allí donde convergen sus lienzos. Este recurso poliorcético junto a otros detalles estilísticos y constructivos singulares es también reconocible en las murallas de la localidad francesa de Aigues-Mortes y en el castillo almeriense. Esta coincidencia se debe, en opinión del historiador Edward Cooper, a la figura de Fernán Gómez de Marañón. Arquitecto presente en las obras de Peñafiel entre 1456 y 1466 que hizo lo propio en Almería entre 1499 y 1502 , y que de alguna manera conocía las defensas del enclave francés, quizás por la vinculación de su benefactor, Pedro de Girón, con la corte de Luis XI.

En lo que respecta a la barrera artillera presente en el castillo almeriense la aparición de estas murallas comienza a implantarse desde la Guerra de Sucesión Castellana (1475-79), conflicto en el que las fortalezas del centro de la Península se mostraron débiles frente a la artillería portuguesa. Esta experiencia estimuló a los ingenieros de la corte a diseñar nuevas murallas alamboradas (ataluzadas para repeler los proyectiles) y de mayor espesor, con las que ofrecer mayor resistencia al fuego invasor, permitiendo además distribuir en su interior puestos artilleros a cubierto desde el pie de cada cubo o cerca, al adarve. Aunque esta defensa ya está presente en el Castillo de La Mota en Medina del Campo (Valladolid) con su segunda barrera construida entre 1476 y 1486, será la del Castillo de Coca (Segovia), provista de foso, barrera artillera y cubos en esquina, la que ofrezca un perfil más parecido al levantado en el castillo almeriense.

\section{La ejecución de las obras del castillo (1490- 1502)}

Tras la capitulación de Almería la corona puso especial empeño en el abastecimiento de alimentos a la población con el envío de barcos cargados de cereal. Para la recepción y venta de estos sustentos los RRCC confiaron en Pedro Pascual; funcionario que desarrolló tareas similares du- rante el aprovisionamiento de Murcia y Vera en 1488. Él fue el responsable de la distribución de víveres en Almería y Tabernas entre 1489 y 1494, siendo los receptores las guarniciones castellanas -como parte de su salario-, los mudéjares, y los nuevos colonos cristianos que comenzaban a habitar este territorio. Lo singular de este hecho es que la venta del grano estaba gravada con un impuesto destinado a la refortificación de la plaza; así con los cuatro reales por fanega de trigo y dos por la de cebaba no sólo se atendían los gastos derivados del transporte marítimo, sino que se contribuía significativamente a financiar las obras (Cooper, 1991, p. 212. Cita: Archivo General de Simancas [AGS], CMC, Leg. 92, "Cuentas de Pedro Pascual del trigo, la cebada, etc., que recibió para el abastecimiento de Almería. Segunda época").

Las cuentas de gastos e ingresos de Pedro Pascual confirman que la construcción del Castillo Cristiano se inició de inmediato (finales de 1489), desarrollándose en dos fases por cuestiones de financiación, una primera hasta 1493 y otra segunda entre 1499 y 1502 en el que cesarán definitivamente los trabajos dejando inacabado el cuerpo de remate de la torre del Homenaje.

En el primer periodo de obras se encuadra también una actuación general de reparación de las murallas y adarves de la Alcazaba vieja, lienzos todos ellos de tapial.

Testigo del avance de las obras sobre el Castillo será en 1494 el viajero austriaco Jerónimo Münzer, de visita por la península huyendo de la peste que azotaba media Europa. De su posterior crónica se extrae la presencia de cautivos en las obras del castillo (García Mercadal, 1952, pp. 305, 348):

"Hallase la ciudad al pie de un monte, en cuya cima se alza una gran fortaleza, y al mediodía está el mar. El rey ha mandado construir un castillo de piedra de sillería sobre los cimientos del antiguo, obra maravillosa [...]. Trabajan allí muchos cautivos con grillos en los pies".

Se completan las descripciones de época sobre la ejecución del castillo con la visita que realizase en 1500 el funcionario de la corona, Jorge de 
Molina, sobre los castillos, torres y estancias de la costa oriental del Reino de Granada. Un excepcional relato de las obras, sus medios humanos, materiales y evolución, incluyendo la descripción métrica en pies castellanos de la planta y alzados del castillo en sus distintas torres y murallas (Garzón, 2015, pp. 133-141).

\section{La conservación de las maltrechas defensas de la plaza de Almería. El terremoto de 1522}

Las necesidades económicas para sostener las obras en el castillo y recomponer el resto de defensas de la Alcazaba vieja encontraron una dificultad añadida, al tener que hacer frente la ciudad al maltrecho estado que ofrecían las extensas murallas que circunvalaban la plaza aún bajo los efectos del terremoto de 1487-, motivo por el que a petición del Concejo de la ciudad, los RRCC concedieron una exención de impuestos y el disfrute de otros (AGS, Registro General de Sello, Leg. 149308, doc. 293, Carta asignando a la ciudad de Almería los propios que en adelante ha de tener, 10 de agosto de 1493), como la explotación de los Herbajes de su jurisdicción, y el Real Privilegio del Derecho del Tigual.

Esta política retributiva se completó en 1504 con la concesión del rey Fernando II de Aragón al Cabildo de una dehesa en el Campo de Níjar, para que con su arrendamiento (herbaje) pudieran contribuir a los gastos generales y de obras (Archivo Municipal de Almería, Leg. 906, Carta Real de D. Fernando el Católico, haciéndole merced de una dehesa en el campo de Nijar, para la ciudad de Almería, 1504).

Estos ingresos, aunque reseñables no eran suficientes para acometer tantos reparos. Tal fue la preocupación de los Reyes y del Concejo local en dotar de medios económicos la conservación de las maltrechas defensas de la plaza de Almería que en 1499 se promulgó una Real Cédula en la que se solicitaba a los ciudadanos originarios de Almería que contribuyeran económicamente a estos trabajos, tal y como lo hacían con la administración saliente (Archivo Patronato de la Alhambra, Leg. L-20-46, Real Cedula de la reina Juana, sobre la contribución de los muni- cipios de Almería en el reparo de los adarves, 1511):

"[...] por parte de la dicha ciudad de Almería nos es fecha relación por su petición diziendo que los muros e torres de dicha ciudad están en algunas partes caydos y mal rreparados e que en tiempo de los reyes moros que fueron del reyno de Granada todos los moros de la tierra e fuero de la dicha ciudad de Almería y de su axarquia contribuían en las labores de los dichos muros e torres de la dicha ciudad por ende que nos suplican e pedían por merced cerca.

A ello mandásemos provello mandando que los dichos moros que solían contribuyr a las dicha labores contribuyesen a ellas [...] como se acostumvrava hazer en tiempos de los dichos reyes moros".

Las dificultades para su cobranza motivaron a que años más tarde (1511) la reina Juana I de Castilla volviera a insistir en esta cuestión.

Inmersos aun en las tareas de recomposición y cierre de brechas de las defensas de la ciudad y su Alcazaba a consecuencia del terremoto de 1487, un nuevo temblor asoló la ciudad en 1522. De la descripción del suceso (Mexia, 1945, p. 317) realizada por el escribano Pedro Mexia años después se extrae:

"Porque en la çibdad de Almería fue tan grande (el terremoto), que derribó la fortaleza y casi todas las torres y muros de la cerca de la çibdad [...]".

Los efectos del sismo fueron relevantes en las murallas medievales de la plaza y en el caserío. En lo que respecta a la Alcazaba, los daños más notables fueron en los lienzos y torres de fábrica antigua.

En respuesta a esta situación y atendiendo a la exposición marítima de la ciudad frente ataques enemigos o pillaje, el rey Carlos I concedió una ayuda anual de 200000 maravedís (recaudada en otros municipios) con la que durante 10 años la corona colaborará en la reconstrucción de las defensas de la plaza, nombrando al teniente alcaide de la Alcazaba, Juan Salcedo, como responsable de la recaudación y administración de estos fondos. Sin embargo, no será hasta 1525 
cuando se inicien las obras debido a que el dinero no había sido librado. Esta circunstancia determinó que el rey reconfirmase la orden con apremio. Por su parte la Alcazaba, cuyas obras se declararon de urgencia, debió seguir esperando hasta 1526-1527 para recibir una actuación puntual y parcial, a juzgar por los informes remitidos por los veedores de la costa del reino de Granada.

\section{La instalación de baluartes artilleros en la Alcazaba vieja}

En 1534 el Marqués de Mondéjar, Luís Hurtado de Mendoza en calidad de Capitán General del Reino de Granada, realizó una visita de reconocimiento del estado de las defensas, tropas, y pertrechos en los principales núcleos marítimos de Granada, Cádiz y Gibraltar, enumerando las carencias, población y recursos económicos, debido a que podían ser objeto de un ataque turco.

Para el caso de Almería, la relación ofrece una visión decadente de la ciudad; mostrándola aún en transición desde su capitulación, con un claro subdesarrollo en comparación a otras localidades del reino. La fortaleza manifestaba aún la escasez de inversiones. Sin más defensas artilleras que las del castillo del tercer recinto. Será por ello, que el Marqués solicite al rey una atención especial, porque en caso de ser ocupada por los turcos, podía ser el origen de una incursión hacia el interior del Reino de Granada, debido a la proximidad de las Alpujarras donde habitaba una mayoría morisca, tachados entonces de colaboracionistas.

La falta de inversiones sobre la Alcazaba dará paso a su decadencia por los múltiples reparos que requería. La desatención principal será por parte de la Tenencia, derecho por el cual la corona ingresaba anualmente al Alcaide, el Duque de Maqueda, Diego de Cárdenas y Enríquez, una suma en concepto de mantenimiento de la instalación. En paralelo las operaciones de castigo y pillaje de los piratas se sucedían sobre este extremo de la costa del Reino de Granada, motivo por el cual su Capitán General redobló los esfuerzos en mantener las instalaciones militares en un adecuado estado para defender las posiciones y resguardar la población. Aceptando esta difícil situación y sus costes económicos el Marqués de Mondéjar encargó la adaptación de la Alcazaba Vieja a la moderna defensa a distancia que permitían las armas de fuego con la implantación estratégica en los recintos primero y segundo de un conjunto de bastiones artilleros con los que defender el perímetro de la fortaleza.

En su mayoría estas intervenciones fueron proyectadas por Luis de Machuca. Maestro mayor de obras del Reino de Granada desde 1549 hasta 1572. Técnico que aprendió el oficio de su padre Pedro de Machuca, quien tras formarse en Italia asumió el cargo de arquitecto militar responsable de las obras de la fortaleza de la Alhambra.

A la muerte de su padre Machuca continuó su labor al frente de las obras de la Alhambra (principalmente en el Palacio de Carlos V), junto con una importante dedicación para la mejora de los emplazamientos defensivos de la costa del Reino de Granada, que incluía las torres y fortalezas diseminadas por el litoral de las provincias de Málaga, Granada y Almería.

Su dedicación a la fortaleza de Almería comenzó en 1550, y se desarrolló hasta 1567, siendo probable que las obras de 1568 también fueran de su traza.

La acomodación de la Alcazaba vieja a los nuevos usos de la guerra incluyó la construcción del Baluarte artillero de la Campana (1550) y la reparación de las puertas principales de la Justicia y la Guardia (1565), completándose el programa edilicio debido a la propagación de la Rebelión de los Moriscos, con la edificación de los Baluartes de San Matías y del Espolón (1568). Estos nuevos bastiones contribuyeron a la defensa de la plaza, aprovechando la posición dominante de la fortaleza sobre el territorio, con una mínima inversión, al tratarse de pequeñas reformas asentadas sobre las viejas murallas de tapial. 


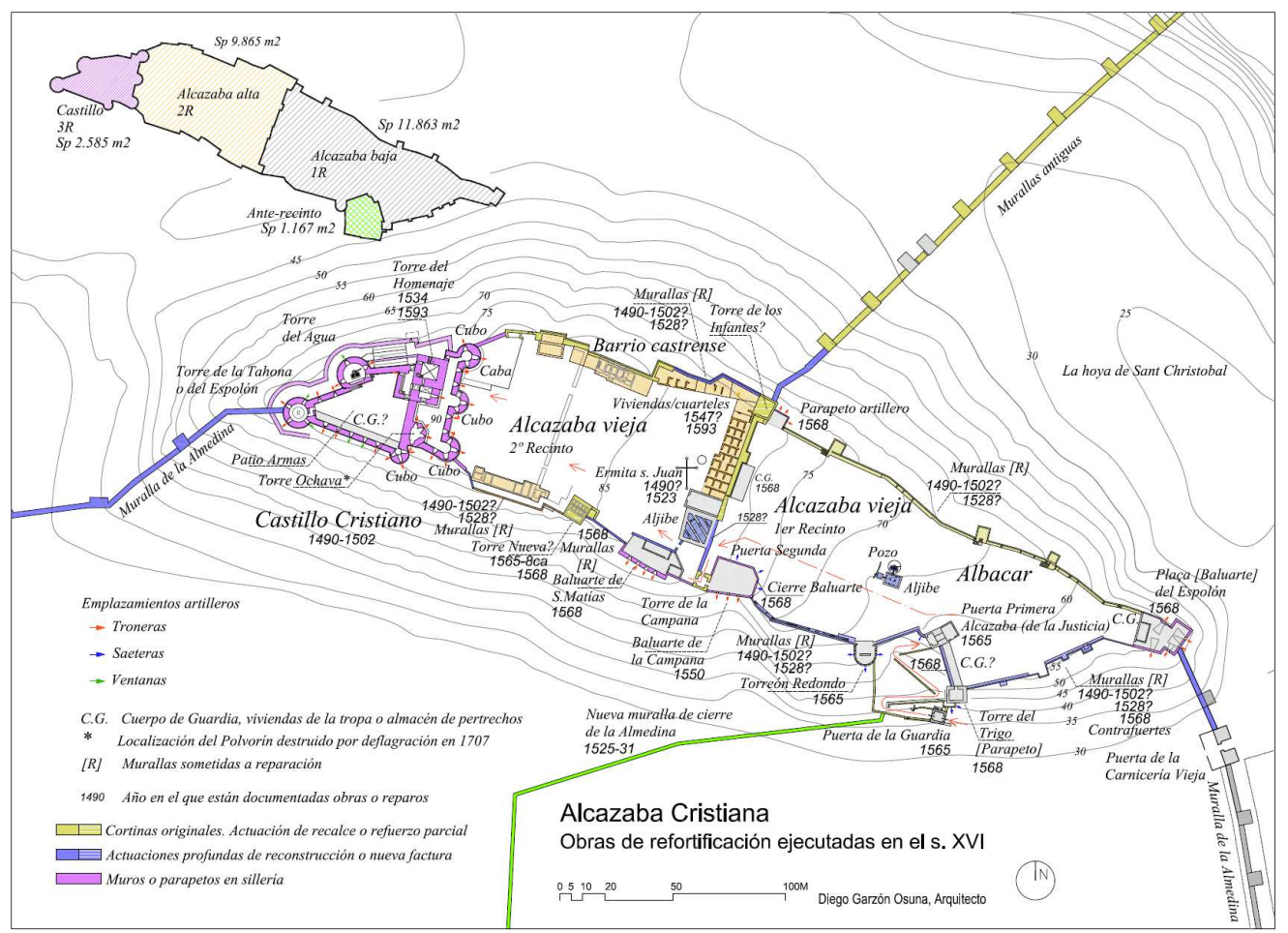

Fig. 2. Alcazaba cristiana. Obras de refortificación ejecutadas en el siglo XVI (Autor).

Estos trabajos cobran especial relevancia, por la minuciosa forma en la que están descritos. En ellos el arquitecto justifica las condiciones que debía cumplir el contratista que se adjudicara las obras, con instrucciones claras sobre como ejecutar recalces de cimentación, muros de sillería de piedra alamborada provistos de troneras y saeteras, armaduras de madera para las cubiertas de los puestos de guardia, el empleo de algas como acabado vernáculo para la cubrición impermeable de cubiertas ligeras o la utilización de morteros de cal aérea con dosificaciones similares a las empleadas hoy.

\section{Conclusiones}

Las incorporaciones cristianas sobre la fortaleza medieval cobran especial relevancia histórica por el momento en el que se suceden, constituyendo un testimonio arquitectónico del periodo de transición entre la edad media y la era mo- derna, con la aplicación de nuevas técnicas constructivas y la adaptación de las defensas a los usos de la pólvora.

Si bien el Castillo Cristiano se conserva en la actualidad aunque desdibujado de su traza original debido a la deflagración accidental del polvorín que guardaba una de sus torres (1707), por el contrario los baluartes artilleros fueron desmontados o cubiertos de almenado (el de San Matías) durante la restauración estilística de la fortaleza acometida tras la Guerra Civil por el arquitecto Francisco Prieto-Moreno.

Estas piezas fueron despreciadas por no ser originales de la Alcazaba hispanomusulmana, debido a que el objetivo era enfatizar el binomio simbólico que ofrecía la Alcazaba medieval y el Castillo Cristiano, visualizando el episodio de la Reconquista de España de forma gráfica, como atractivo de la incipiente industria turística. 


\section{Bibliography}

Cooper, E. (1991). Castillos señoriales en la corona de Castilla, Junta de Castilla y León, Salamanca, Vol. I.1.

Fernández de Palencia, A. (2012). Guerra de Granada, Linkgua Red ediciones S.L, Barcelona.

Gámir Sandoval, A. (1958). Las fardas para la costa granadina (Siglo XVI), Universidad de Granada, Granada.

García Mercadal, J. (1952). Viajes de extranjeros por España y Portugal, Aguilar, Madrid.

Garzón Osuna, D. (2015). Compendio de obras en la plaza militar de Almería y su Alcazaba, Tesis Doctoral, Universidad de Granada, Granada.

Mexia, P. (1945). Historia del Emperador Carlos V, Espasa Calpe, Madrid.

Torres Balbás, L. (1957). “Almería Islámica”, Al-Ándalus, Revista de las Escuelas de Estudios Árabes de Madrid y Granada, XXII. 